\title{
Modelling mineral dust in the Central Asian region
}

\author{
Bernd Heinold ${ }^{1, *}$ and Ina Tegen ${ }^{1}$ \\ ${ }^{1}$ Leibniz Institute for Tropospheric Research, Department Modelling of Atmospheric Processes, 04318 Leipzig, Germany
}

\begin{abstract}
In Central Asia, climate and air quality are largely affected by local and long-travelled mineral dust. For the last century, the area has experienced severe land-use changes and water exploitation producing new dust sources. Today global warming causes rapid shrinking of mountain glaciers with yet unknow consequences for dust and its climate effects. Despite the importance for a growing population, only little is known about sources, transport pathways and properties of Central Asian dust. A transport study with a global aerosol-climate model is undertaken to investigate the life cycle of mineral dust in Central Asia for the period of a remote-sensing campaign in Tajikistan in 2015-2016. An initial evaluation with sun photometer measurements shows reasonable agreement for the average amount of dust, but a significant weakness of the model in reproducing the seasonality of local dust with maximum activity in summer. Source apportionment reveals a major contribution from Arabia throughout the year in accordance with observations. In the model, local sources mainly contribute in spring and autumn while summer-time dust production is underestimated. The results underline the importance of considering long-range transport and, locally, a detailed representation of atmospheric dynamics and surface characteristics for modelling dust in Central Asia.
\end{abstract}

\section{Introduction}

Central Asia is a hot spot of climate change [1] and both source and receptor area for mineral dust aerosol. After dramatic land-use changes forming new dust sources in the last century, Central Asia today is facing a dramatic shrinking of high mountain glaciers due to global warming with yet unclear impacts by and on mineral dust $[2,3]$. However, despite the potential importance of dust as an important factor impacting climate and air quality in this region, only little information on dust sources, transport pathways and effects are available so far.

Central Asia is covered by a mixture of different types of deserts and drylands, which represent important dust sources accounting for at least $10 \%$ of global dust emissions [4]. Dust production is most active in mountain foothills and deserts of alluvial origin. The deserts Karakum and Kyzylkum and the Caspian Sea coast are the most important natural sources of Central Asian dust [5]. As a result of man-made desertification, the Aral Sea is the largest single dust source in this area today [6]. In addition, Central Asia is influenced by considerable loadings of long-travelled dust from the Saharan and Arabian deserts.

To date, estimates of the dust impact on weather and climate for Central Asia are highly uncertain due to uncertainties and the large variability of the dust properties. Only few measurements exist to quantify dust from the different source regions. A first attempt to comprehensively characterize Central Asian dust was made in a joint Soviet-American field experiment in Tajikistan back in 1989 [7]. Since recently, the first long-term vertical profiling of aerosol optical and radiative properties in Tajikistan is available from lidar measurements within the project Central Asian Dust Experiment (CADEX; [8]). The observations show a large range of dust layering conditions throughout a year [9], and are of particular value for dust modelers.

The complex topography and the range of different source types make the modelling of the Central Asian dust cycle (emission, transport and deposition) challenging. One of the challenges is to reproduce the typical seasonality with the main dust activity from March to October peaking in summer months as well as long-term trends and inter-annual variability. Global aerosol-climate models consistently underestimate dust optical depths over Asian desert regions in all seasons, except autumn when the dust load is generally low [10]. The results from a regional sensitivity study show the importance of an accurate representation of the dynamic surface characteristics (land cover, soil moisture and crusts, surface roughness) as well as soil properties [11, $4,12]$. A critical issue is the mismatch between input parameters available at model resolution and the subgrid scale requirements of sophisticated dust schemes.

In this study, the global aerosol-climate model ECHAM6.3-HAM2.3 is used to investigate the sources and transport pathways of mineral dust in Central Asia. The simulations initially cover the CADEX campaign period from spring 2015 to summer 2016. Sun photometer measurements at the CADEX site in

\footnotetext{
* Corresponding author: bernd.heinold@tropos.de
} 
Dushanbe, Tajikistan and at surrounding AERONET stations are used for an initial evaluation of the model performance. In order to quantify the contribution of the different local and distant sources to the dust load over Central Asia, source apportionment experiments are conducted. Ultimately, the model results help to understand the distribution and climate impact of mineral dust in the Central Asian region.

\section{Methods}

For this dust transport study, the global aerosol-climate model ECHAM6.3-HAM2.3 is used, which consists of the general circulation model ECHAM6 [13] and the interactive-aerosol module HAM2 [14]. The model simulates the global formation, transport, and removal of aerosol particles in the atmosphere, their processing and interactions. Aerosol populations, which can be internally or externally mixed, are described by a superposition of seven log-normal modes. The aerosol removal from the atmosphere is due to sedimentation, dry and wet deposition, and is parameterized in depending on particle size, composition, and mixing state. The modelled aerosol distribution can affect the climate simulations through interactions with radiation and clouds. The emissions of mineral dust aerosol are computed online, based on the ECHAM6 meteorology using the scheme by [15].

ECHAM6.3-HAM2.3 is used at about $1.8^{\circ}$ (T63) horizontal resolution and operated in nudged mode to follow the observed meteorology using ECMWF reanalysis. The modelled period covers the CADEX campaign, which took place from March 2015 to August 2016.

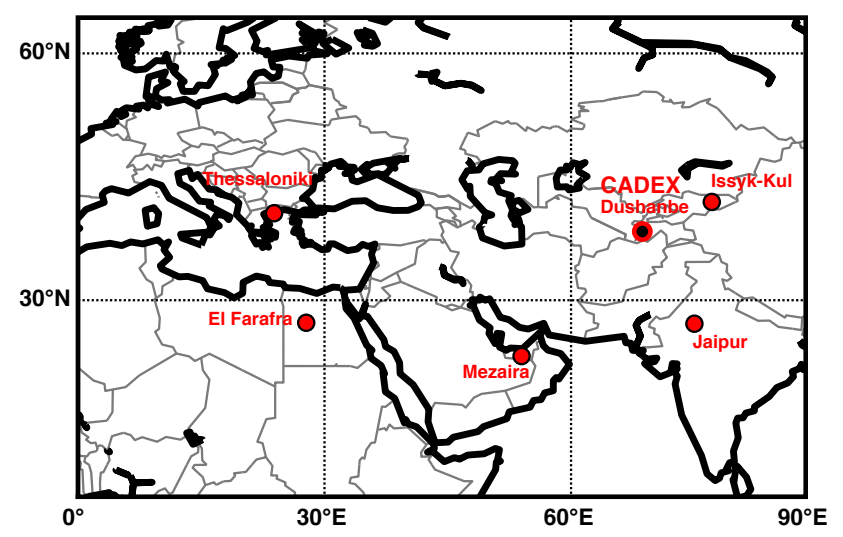

Fig. 1. Map showing the location of the CADEX field site in Dushanbe, Tajikistan and surrounding AERONET stations used for model evaluation.

The modelled dust is initially evaluated using the sun photometer derived coarse-mode aerosol optical depth (AOD) at the CADEX site in Dushanbe, Tajikistan and at surrounding AERONET stations (see Fig. 1 for their location). Further evaluation will also include routine satellite observations of aerosol and the CADEX lidar profiles.

Source apportionment studies allow to explicitly assess the contribution from the different Central Asian deserts and distant source regions (e.g., Sahara, Arabian and Taklimakan Desert). Here, a simple method is applied, where the main relevant dust source regions: Central Asia, Middle East, North Africa, and East Asia are alternately switched off in separately performed simulations.

\section{Results}

The initial evaluation of the model results highlights the challenges of dust modelling in Central Asia. Timing as well as placement of modelled dust emission events so far do not always satisfyingly agree with satellite imagery and sun photometer observations. Figure 2 shows the 2015 monthly means of modelled dust optical depth compared to coarse-mode AOD at the CADEX field site Dushanbe and AERONET stations in the direction of main transport pathways.

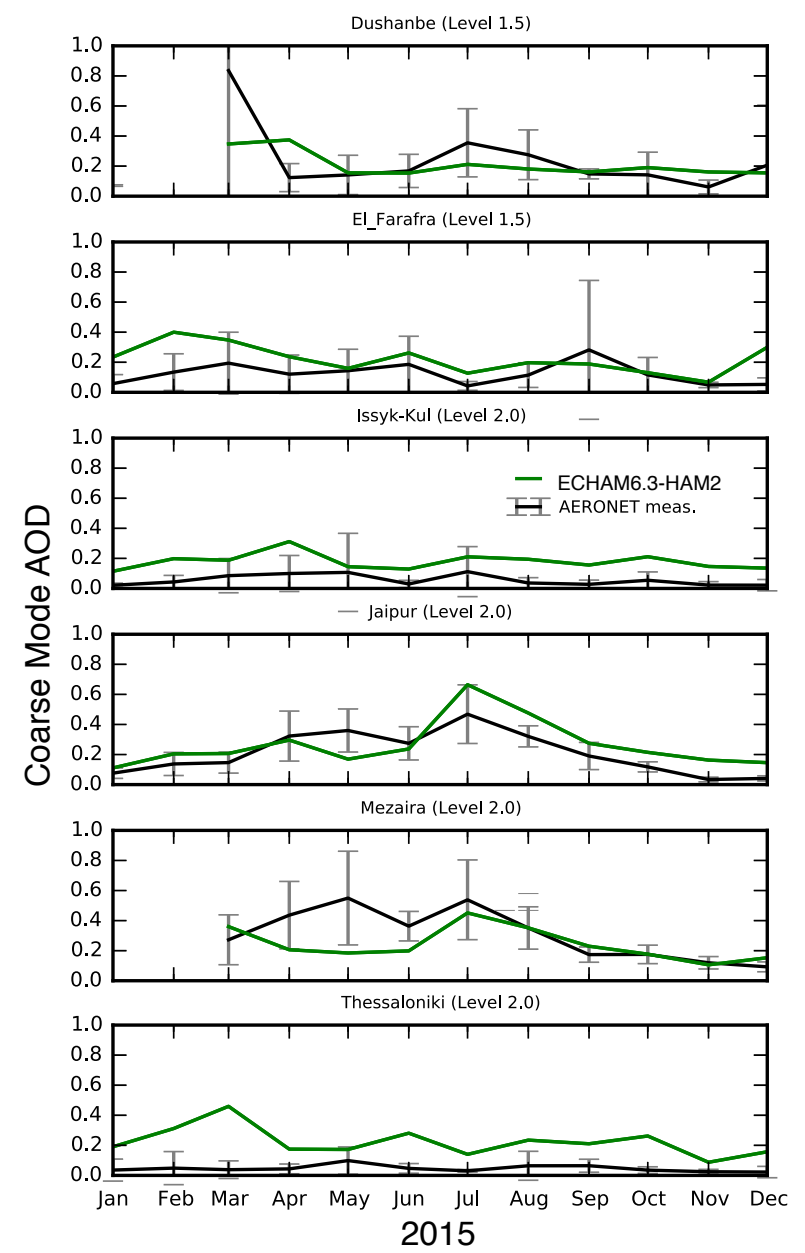

Fig. 2. Aerosol optical depth (AOD) at Dushanbe, Tajikistan and surrounding AERONET stations. Compared is the AERONET 500-nm coarse-mode data (black line) and the modelled dust AOD from ECHAM6.3-HAM2.3 (green line).

At Dushanbe, the measurements show unusual high values in March and a typical maximum around July with a coarse-mode AOD of up to 0.4. The model, however, produces high dust AODs up to 0.4 in March 
and April but relatively constant values around 0.2 through the rest of the year.

A good agreement in seasonal variability is found for the AERONET stations south of Central Asia. In particular at the Arabian site Mezaira and at Jaipur on the Indian Peninsula the annual evolution of modelled dust matches well the observations with a distinct summer maximum of 0.5 to 0.6 , respectively.
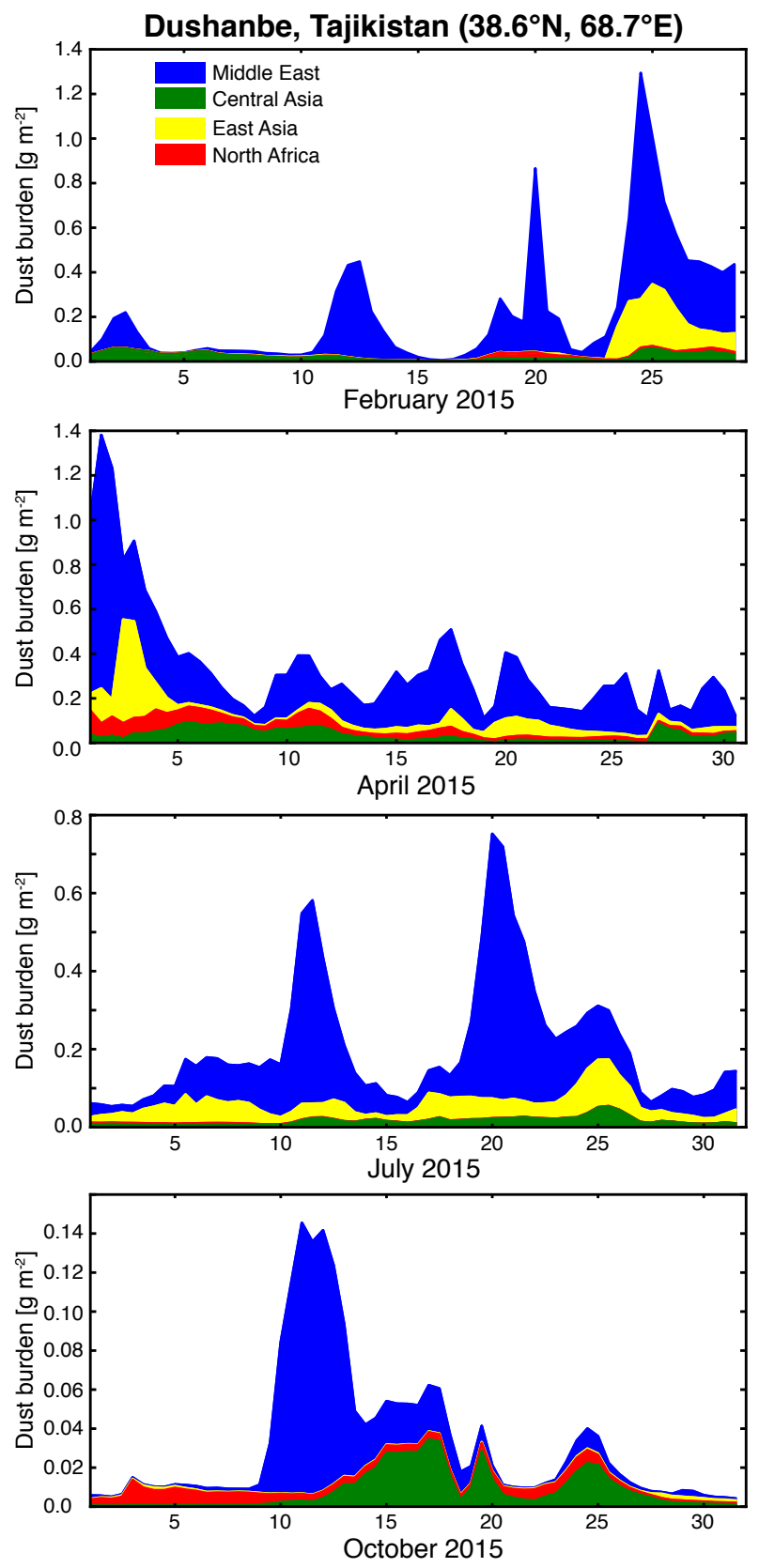

Fig. 3. Mineral dust source apportionment at the CADEX station Dushanbe, Tajikistan for different month in the year 2015, based on ECHAM6.3-HAM2.3 model results (note the different scales).

In the West, however, at Thessaloniki the model overestimates the dust AOD with values of up to 0.4 in early spring and approximately 0.25 during other months while the measurements are around values of 0.1 throughout the year 2015. This shows that long-range transport from southerly and south-westerly directions is well captured by the ECHAM6.3-HAM2.3 model, but the advection of Saharan dust across the Mediterranean and Black Sea towards Tajikistan is likely overestimated. Regarding local sources, further analysis of potential reasons for the mismatches and appropriate model improvements are required. In particular, the representation of preferential dust sources and nearsurface winds in the complex topography of Central Asia needs to be evaluated in detail.

The results of the source apportionment experiments are presented in Fig. 3. Shown is the modelled dust burden at Dushanbe split according to the main local and distant source regions: Central Asia, Middle East, North Africa, and East Asia for selected months in 2015.

The total dust burden computed by ECHAM6.3HAM2.3 varies considerably between seasons, ranging up to $0.15 \mathrm{~g} \mathrm{~m}^{-2}$ in October and $1.5 \mathrm{~g} \mathrm{~m}^{-2}$ in July. A major contribution of Arabian dust is simulated throughout the year 2015 in accordance with the CADEX observations (Hofer et al., 2017). This is followed by dust transport from East Asia. Saharan sources are especially important in April and October.

Central Asian sources mainly contribute to the dust burden in spring and at a generally lower level in autumn (Fig. 3). However, as already indicated by the AOD comparison in Fig. 2, the fraction of local dust events during summer months might be underestimated in the ECHAM6.3-HAM2.3 simulations.

\section{Summary and outlook}

This study aims to enhance the understanding of mineral dust in Central Asia. The area is affected by locallyproduced and long-travelled dust. Despite its potentially important role for climate and air quality in this region, only little is known about sources, transport pathways and effects.

Global dust simulations with the aerosol-climate model ECHAM6.3-HAM2.3 are performed with approximately $1.8^{\circ}$ grid spacing for spring 2015 to summer 2016 in order to investigate the life cycle of dust in Central Asia. An initial evaluation of the model results with coarse-mode AOD retrievals from field measurements at Dushanbe, Tajikistan during the CADEX experiment in 2015-2016 as well as from the AERONET network shows reasonably good agreement in the amount of dust. However, reproducing the typical seasonality of Central Asian dust with activity peaking during the summer months is more challenging. Ongoing model evaluation will in particular include the first longterm aerosol lidar profiling from the CADEX field experiment for evaluating and constraining the dust layering in Central Asia.

The results of source partitioning simulations with ECHAM6.3-HAM2.3 highlight the importance of considering long-range transport and local emissions for modelling Central Asian dust. While local dust production is likely underestimated by the model, in particular the important contribution from Arabian deserts throughout the year matches the observations. The challenge here is to combine global coverage with 
high resolution for an appropriate representation of atmospheric dynamics and surface characteristics in the complex mountainous terrain of Central Asia. The model evaluation will therefore be continued with latest soil and land-cover data at high spatial and temporal resolution. In addition, the application of a mesoscale dust model is envisaged for a detailed modelling of local dust production.

Ultimately, the ECHAM6.3-HAM2.3 simulations of mineral dust in this study help better characterise dust emission and transport as well as dust feedback mechanisms and climate forcing in the Central Asian region.

The authors are grateful for computing resources granted at DKRZ. The ECHAM-HAMMOZ model is developed by a consortium composed of ETH Zurich, Max Planck Institut für Meteorologie, Forschungszentrum Jülich, University of Oxford, the Finnish Meteorological Institute and the Leibniz Institute for Tropospheric Research, and managed by the Center for Climate Systems Modeling (C2SM) at ETH Zurich. We thank Sabur F. Abdullaev for his efforts in establishing and maintaining the AERONET site Dushanbe, Tajikistan.

\section{References}

1. F. Giorgi, Geophys. Res. Lett., 33, L08707 (2006)

2. E. Lioubimtseva and G.M. Henebry, J. Arid Environ., 73(11), 963-977 (2009)

3. D. Farinotti, et al., Nat. Geosci. 8, 716-722 (2015)

4. X. Xi and I.N. Sokolik, J. Geophys. Res. Atmos., 120, 12.175-12.197 (2016)

5. G. Issanova and J. Abuduwaili, Aeolian processes as Dust Storms in the Deserts of Central Asia and Kazakhstan (Springer Nature, Singapore, 2017)

6. P. Micklin, Annu. Rev. Earth Planet. Sci., 35, 47-72 (2007)

7. G. Golitsyn and D.A. Gillette, Atmos. Environ., 27, 2467-2470 (1993)

8. D. Althausen, et al., Light, Energy and the Environment, OSA Technical Digest (Optical Society of America, 2016)

9. J. Hofer, et al., Atmos. Chem. Phys., 17, 14559-14577, (2017)

10. D.A. Ridley, C.L. Heald, J.F. Kok and C. Zhao, Atmos. Chem. Phys., 16, 15.097-15.117 (2016)

11. M. Ferrat, B. Langmann, X. Cui, J. Gomes, and D.J. Weiss, J. Geophys. Res. Atmos., 118, 4597-4609 (2013)

12. X. Xi and I.N. Sokolik, J. Geophys. Res. Atmos., 120, 1536-1564 (2015)

13. B. Stevens, et al., J. Adv. Model. Earth Syst., 5 (2013)
14. K. Zhang, et al., Atmos. Chem. Phys., 12, 8911-8949 (2012)

15. I. Tegen, et al., J. Geophys. Res., 107(D21), 4576 (2002) 